\title{
Wind energy storage by pumped hydro station
}

\author{
Mariem Naciri \\ Laboratory of Renewable Energies and Environment (LR2E) Department of Physics, Faculty of Science, IBN TOFAIL University, \\ Kenitra, Morocco,nacirimariem@gmail.com ORCID ID: 0000-0003-3809-4375 \\ Mohammed Aggour \\ Laboratory of Renewable Energies and Environment (LR2E) Department of Physics, Faculty of Science, IBN TOFAIL University, \\ Kenitra, Morocco ORCID ID: 0000-0001-5801-1958 \\ Wassima Ait Ahmed \\ Laboratory of Renewable Energies and Environment (LR2E) Department of Physics, Faculty of Science, IBN TOFAIL University, \\ Kenitra, Morocco ORCID ID: 0000-0002-6056-6538 \\ Arrived: 18.07.2017 Accepted: 13.09.2017 Published: 17.09.2017 \\ Naciri,M. L. Aggour,M. Ahmed, WA. Wind energy storage by pumped hydro station, \\ Journal of Energy Systems 2017, 1(1),32-42, DOI: 10.30521/jes.329315
}

Abstract: During the next decades, the electricity generation sector will know significant changes. This is mainly due to the increase in demand, with the limitation of traditional resources such as fossil fuels and the development of renewable energy particularly the proliferation of wind farms. Hydroelectric pumped-storage power plants, which store large amounts of energy and quickly compensate the power fluctuations, will then play a key role. It is therefore essential to find ways to fully optimize the performance of this type of plant. The main objective of this work is to study and choose the right place according to different criteria, topographical, geographical in order to install a pumped hydro station we try to size. All this is in order to ensure network stability. Such a study requires two main pumped hydro stations, namely the theoretical development and case study part. With the arming out of the three wind farms developed by Nareva holding, a major leader company in the domains of the energy and the environment, Akhfennir and Foum El Oued in the South of Morocco, and Haouma in the north of the country near to Tangier, these three parks, of a total capacity of 203 MW. Storing the surplus of the wind produced energy became a priority, hence we led a detailed study on six sites on various region of Morocco to install a hydraulic pumping station of a power of 50MW.The pumped hydro station of Abdelmoumen is situated in the upstream of the restraint of the dam Abdelmoumen on the Wadi Issen in approximately 70 kilometres in the Northeast of the city of Agadir. The study of the sizing of the pumped hydro station of Abdelmoumen led to us to the conception of a station of 50MW of power for a height difference of $800 \mathrm{~m}$ separating both upper and lower reservoirs whose volumes are respectively $2610000 \mathrm{~m}^{3}$ and $749700 \mathrm{~m}^{3}$. We conceived a Pelton turbine with a debit of turbinage of $8 \mathrm{~m}^{3} / \mathrm{s}$, a pump spin-dries radial road of $2,4 \mathrm{~m}^{3} / \mathrm{s}$ and penstock of $6691 \mathrm{~m}$ of $1 \mathrm{~m}$ of diameter.

Keywords: Wind energy; pumping station; energy production; wind turbine; turbine components.

(C) 2017 Published by JES peer-review scientific journal at DergiPark (www.dergipark.gov.tr/jes)

Nomenclature

\begin{tabular}{|c|c|c|c|}
\hline$P_{h}$ & Hydraulic & $\Delta \mathrm{P}_{\mathrm{I}}$ & of lood \\
\hline $\begin{array}{l}h \\
\rho\end{array}$ & Density of the water $\left[\mathrm{kg} / \mathrm{m}^{3}\right]$ & $\Delta$ Linear & Coefficient of friction \\
\hline$\sigma$ & Acceleration of the gravity $\left[\mathrm{m} / \mathrm{s}^{2}\right]$ & $\mathbf{I}$ & I onoth of the ninclings [m] \\
\hline $\mathrm{g}$ & & & Lengut or tile pipentines [II] \\
\hline Q & Flow rate slogged $\left[\mathrm{m}^{3} / \mathrm{s}\right]$ & $\operatorname{Re}$ & Reynolds number \\
\hline $\mathrm{H}$ & Fall in $[\mathrm{m}]$ & $\vartheta$ & Kinematic viscosity of the fluid $\left[\mathrm{m}^{2} / \mathrm{s}\right]$ \\
\hline $\mathrm{r}$ & Efficiency on the hydroelectric power plant & K & Coefficient of loss of singular load \\
\hline V & Speed of the fluid $[\mathrm{m} / \mathrm{s}]$ & $\eta_{\text {cycle }}$ & Losses of loads on a cycle \\
\hline $\mathrm{S}$ & Section of passage $\left[\mathrm{m}^{2}\right]$ & $\eta_{\text {pipes }}$ & Efficiency in pressure pipes \\
\hline $\mathrm{D}$ & Diameter of the section of passage $[\mathrm{m}]$ & $\eta_{\mathrm{T}}$ & Efficiency of the turbine \\
\hline $\mathrm{N}$ & Rotation velocity [tr/min] & $\eta_{P}$ & Efficiency of the pump \\
\hline $\mathrm{Hg}$ & $\begin{array}{l}\text { Geometrical height in the inhalation }+ \\
\text { geometrical height in the expulsion [m] }\end{array}$ & $\eta_{\text {alt }}$ & Efficiency of the alternator \\
\hline$\Delta p c$ & Losses of loads in the installation & $\eta_{\text {transf }}$ & Efficiency of the transformer \\
\hline$T M H$ & Total manometric height & $L L_{t o t}$ & Total losses of load \\
\hline
\end{tabular}




\section{INTRODUCTION}

The increasing request in electricity and the progressive exhaustion of the fossil sources of energy (oil, gas, coal) and their ecological inconveniences (global warming of the planet caused by the greenhouse gas emission) urge the humanity to turn to new renewable sources of energy which are unlimited, non-polluting and whose exploitation causes fewer damages on the environment [1].

Among all the renewable energies contributing to the electric production, the wind energy holds at present an important role. For centuries, the man uses the wind energy to take forward boats, grind of the grain or pump some water. This source of energy serves us to produce some electricity and, it is the source of electricity, which grows most quickly in the world. Since a few years, the wind electric production was in full industrial development [2]. It is first the not polluting renewable energy, which contributes to a better air quality and to a fight against the greenhouse effect. Also an energy uses the national resources and thus contributes to the energy independence.

However, an important characteristic of the wind energy is the fluctuation of its power production over time. Thus, the stability of the network bases on the balance enter production and consumption. For that purpose, the idea of storage was exploited [3]. Indeed, storing energy is the key of penetration of the wind energy in an electric system because it supplies not only a technical solution to the administrator of the network to assure in real time the balance production / consumption, but he also allows to exploit at the most renewable resources of energy by avoiding the un-ballasting.

The administrator of the electricity network compensates for the residual variability of the wind energy by using other sources of production and the offered storage capacity, in particular by the water of dams, water retention and the stations of transfer of energy by pumping [4].

The wind production joins well to the hydroelectric power: if the production is more important than planned, the wind electricity can be used to pump the water of a low water retention in a higher water retention and make so stocks of hydroelectric power. If the production is less important than planned, dams, pumped hydro station or the interconnections can supply the complement to electricity. So, the development of the wind energy confronts not only in number of wind turbines, but also in the evolution of the electric system [5].

During the study, I worked on an interesting theme the storage of the wind energy of three wind farms by the method of the station transfer of energy by pumping.

\section{WIND ENERGY}

The mission of storage is thus important for optimizing the electric storage and improving the integration of the renewable energies in the electricity network. According to the detractors of the wind energy, we could not store the mass energy. What would be a handicap for the development of the wind electricity production? What is not the case because to store massively the energy stemming from the night-overproduction of our wind farms we resort to the stations of transfer of energy by pumping it appears as a good solution [6].

In the world: more than $100 \mathrm{GW}$ is installed in pumped hydro station, distributed on approximately 380 works which cover more than $99 \%$ of the total capacities of storage of electricity today [7]. The pumped hydro station plays an important role with the democratization of occasional sources of energy, as the wind energy or the solar energy, who oblige to store a part of the production in order to not lose it.

The production of wind turbines cannot be modulated at will to adapt it to the needs for the consumers, it shares this characteristic with the other energies produced directly by fluctuating natural sources of energy [8]. The wind production depending directly the strength of the wind is very fluctuating. To store the occasional energy is the major problem, it is necessary to analyze first of all the production of three parks.

The stored energy amount can then be used to satisfy part of local load demand when there is power deficit, in case that local power generation is insufficient to cover the entire electrical needs [9].

\section{ANALYSIS OF WIND FARMS PRODUCTION}

Between 50,6 MW for each of the sites of Haouma and Foum El Oued and 101,87 MW of Akhfennir. We will develop the daily, monthly and annual graphs of production of the three wind farms.

\subsection{Daily Production}

The graphs of daily electricity production below reflect the daily lifestyle of the three wind farms, this curves have approximately the same form [Figure 1]. 


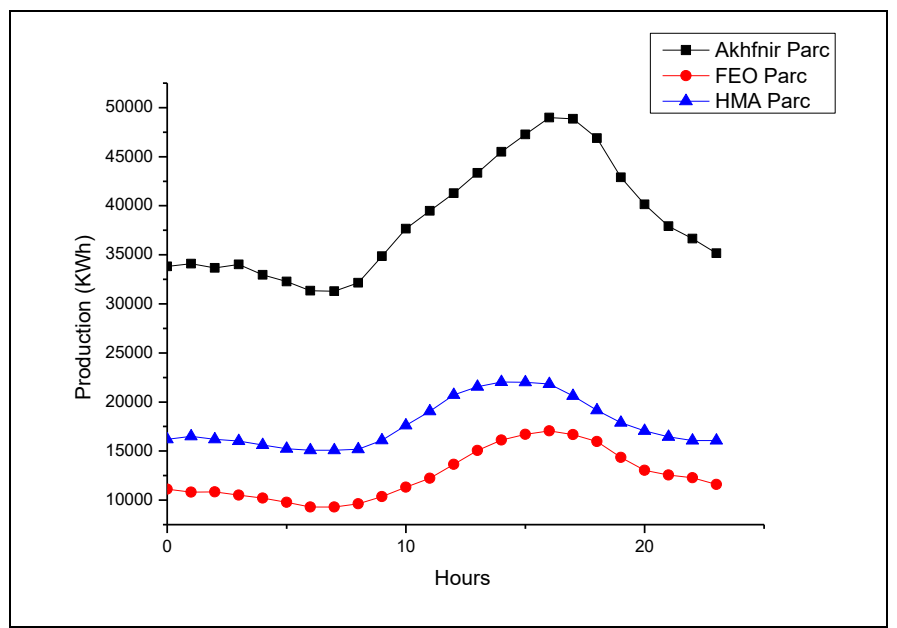

Figure 1: Daily wind production of the 3 wind farms

For the park of Haouma situated in the north of the Morocco, in Tangier, its curve knows a progress from 10 am until $6 \mathrm{pm}$, we notice a peak arriving until $23 \mathrm{MW}$ at $3 \mathrm{pm}$.

For the park of Foum Eloued situated in the south of the country its maximal power reaches 17 MW for a period of 5 hours from $1 \mathrm{pm}$ to $6 \mathrm{pm}$ and decreases during the day, the power of this park knows a peak at 5 pm its minimal power is $10 \mathrm{MW}$.

For the park of Akhfennir in the South of Morocco its maximal power lengthens from 10 am to 7 pm knows a peak at $5 \mathrm{pm}$ reaching 50MW then decreases until $29 \mathrm{MW}$ towards $7 \mathrm{am}$.

\subsection{Monthly Production}

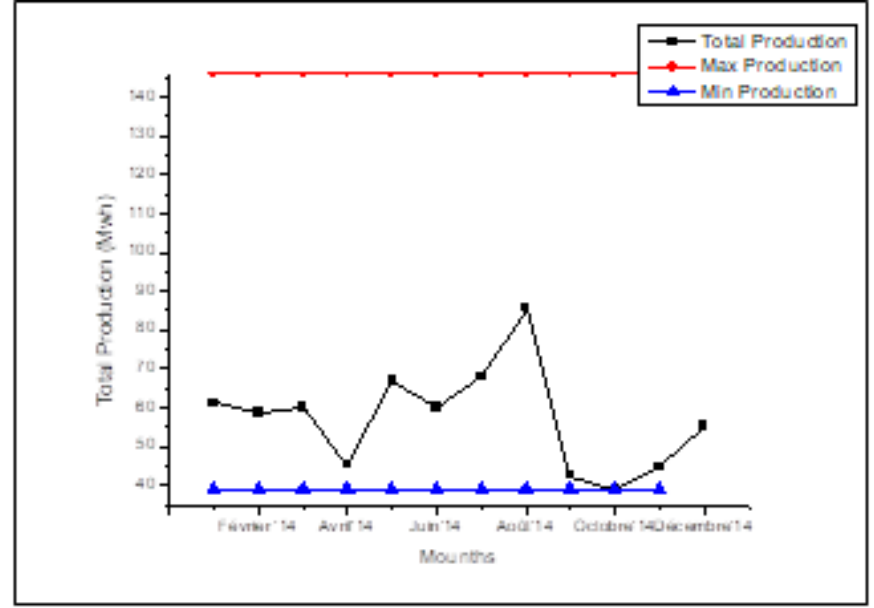

Figure 2: Monthly wind production of the 3 wind farms

\subsection{Annual Production}

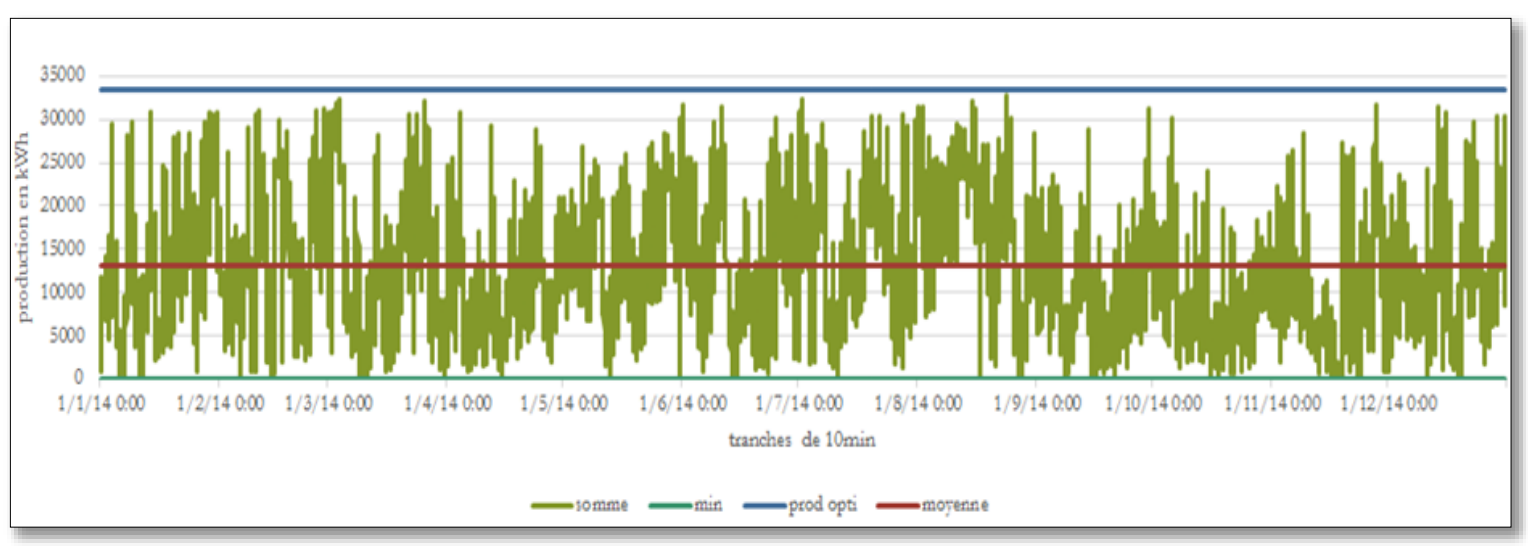

Figure 3: Annual wind production of the 3 wind farms 
The following graph [figure 3] represents the total production of three wind farms by slice of $10 \mathrm{~min}$. We notice a very big variation of production that can reach $34 \mathrm{MWh}$ as maximum value and an average of production of $13 \mathrm{MWh}$. Taking into account these results we wish to store a power of 50MW.

\section{STUDY OF THE SIZING OF THE PUMPED HYDRO STATION}

The technique of storage of the most developed and most used around the world is the station of transfer of energy by pumping [6]. The pumped hydro station has a significant role in the energy transition and the preservation of the balance between production and consumption of electricity, an answer to the challenge of the irregularity of the renewable energies. The pumped hydro station must be studied and designed according to very precise stages [10]. Generally, the study of the prefeasibility of a pumped hydro station is done into two major phases: the pre-identification of the potential sites and the techno-economic study of the reserved site.

\subsection{The pre-identification of the potential sites}

A site must meet certain criteria for evaluation:

- Topographic criterion

- Accessibility to the site

- Geographical context

- Environmental description

Further to the identification and the preselection of sites adapted for the installation of the pumped hydro station and on the basis of the criteria quoted previously a complete analysis was realized. Among the likely sites, we chose six sites that are the most suited to the analysis, for which we used the appropriate tools for our study.

\subsection{Used Tools \\ Google earth}

A software, a property of the company "Google", allowing a display of the Earth with an assembly of air or satellite photos it also allows to go directly to a place by entering its mailing address, its coordinates or either by navigating manually. Google Earth is also provided with the topographic data gathered by the "NASA" during the mission "SRTM", which allows posting the surface of the Earth in 3D. Yet in our case it is for the location of sites as well as their coordinates, it will help us spot if there are roads accessible to the site, if there are agricultural surfaces as well as houses near the site.

\section{Global mapper15}

A SIG application accessible and easy to use, which gives access to diversified sets of spatial data and just supplies the good level of features to satisfy at the same time the experimented professionals of the SIG and beginners. It is an autonomous spatial management tool of data and an integral part of a SIG of company in the scale, Global Mapper is a gaunt best for all those who deals with maps or spatial data.

For our study, this software helped us to determine the reserved theoretical height corresponds to the peak of the site, the potential surfaces for the setting-up of the upstream reservoirs and downstream one. It determines also the length of necessary pipelines between the upper and lower reservoirs as well as between the lower pond and the source of water; dam in our case.

\subsection{The Pre-Selected Sites}

- Abdelmoumen dam situated in the south of Morocco.

- Moulay Abdellah dam in the South of Morocco.

- Al Wahda dam.

- Al Hansali dam.

- Asmir dam in the Rif.

- Midelt dam atlas of Morocco. These sites are noted in the map [figure 4] 


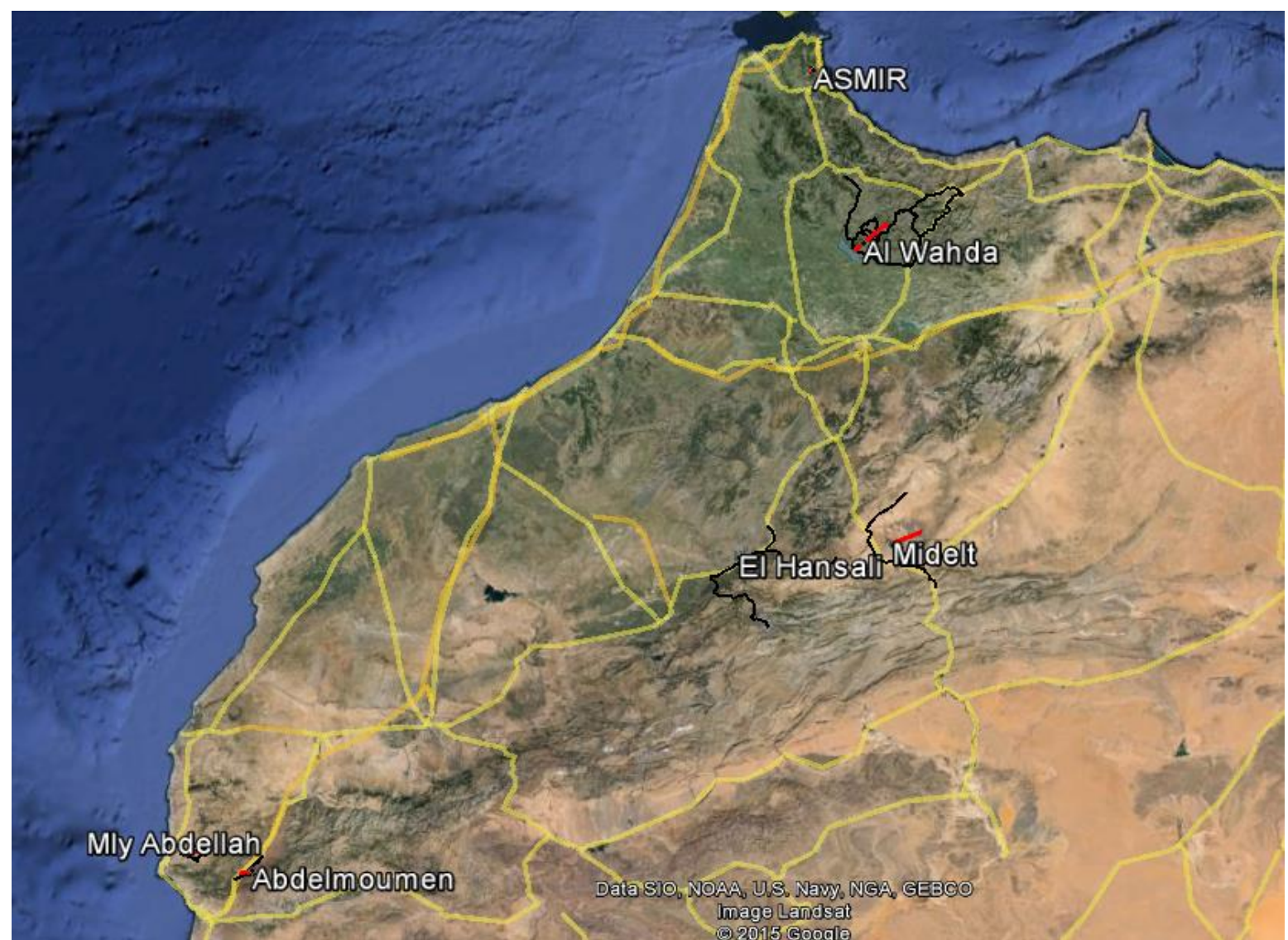

Figure 4: Sites selected represented on google earth

\section{Topographic criterion}

We gathered the topographic data of the various sites on the table that follows [Table 1]

Table 1: Topographic criteria of six pre-selected sites

\begin{tabular}{lcccccc}
\hline \multicolumn{1}{c}{ Sites } & $\begin{array}{c}\text { Highlight } \\
(\mathrm{m})\end{array}$ & $\begin{array}{c}\text { Distance Upstream- } \\
\text { approval }(\mathrm{m})\end{array}$ & $\begin{array}{c}\text { Uneven } \\
(\mathrm{m})\end{array}$ & $\begin{array}{c}\text { upstream } \\
\text { surface }\left(\mathrm{m}^{2}\right)\end{array}$ & $\begin{array}{c}\text { downstream } \\
\text { surface }\left(\mathrm{m}^{2}\right)\end{array}$ & $\begin{array}{c}\text { Outstrip lower } \\
\text { pond and dam }(\mathrm{m})\end{array}$ \\
\hline ASMIR & 740 & 102 & 600 & 980000 & 261500 & 2027 \\
AL WAHDA & 1500 & 8469 & 1250 & 787000 & 254400 & 21019 \\
AL HANSALI & 1600 & 4960 & 700 & 762000 & 284000 & 7249 \\
MIDELT & 1550 & 1183 & 280 & 877000 & 225200 & 18209 \\
MLY ABDELAH & 960 & 2680 & 660 & 540000 & 243000 & 2142 \\
ABDELMOUMEN & 1550 & 3980 & 750 & 1246000 & 258000 & 2801 \\
\hline
\end{tabular}

\section{Accessibility to the site}

The site must be accessible, for the pre-selected sites, roads and tracks already exist.

\section{Geographical context}

We can divide Morocco into four big regions:

The Rif: recent mountain range, formed in the Tertiary sector it is a member of alpine chains which result from the collision Africa-Eurasia and more exactly in the chain Rifotellienne of North Africa.

The Atlas: Middle Atlas and High Atlas. Are members of the chain atlas, formed in the Tertiary sector. It is a chain intercontinental, situated in the African continent. She extends from Morocco to Tunisia and establishes the front-country deformed of the chain Rifotellienne

The Meseta: regions of plains, trays, hills. We distinguish western Meseta and oriental Meseta separated by the Middle Atlas

The Moroccan South (Anti-Atlas): it is the Saharan domain the limit of which corresponds in the South fault Atlas. We distinguish Anti Atlas, mountainous region in the South of the Top Atlas resulting from a vast recent anticline wrinkling and, beyond, Sahara cleanly, region of vast plains and desert trays. 


\section{Environmental description}

Always in the concern of a harmonious urban development, a particular attention has to be lent to the esthetic and landscaped considerations of the territory by considering the impact of the visibility of the site

\section{Site selected for the installation of the pumped hydro station}

Based on a notation system we chose the appropriate site of the conception of the pumped station.

We obtained the table below [Table 2].

Table 2: Topographic criteria of six pre-selected sites

\begin{tabular}{lcccccc}
\hline \multicolumn{1}{c}{ Sites } & $\begin{array}{c}\text { Distance } \\
\text { Upstream- } \\
\text { approval } \\
(\mathrm{m})\end{array}$ & $\begin{array}{c}\text { Uneven } \\
(\mathrm{m})\end{array}$ & $\begin{array}{c}\text { upstream } \\
\text { surface } \\
\left(\mathrm{m}^{2}\right)\end{array}$ & $\begin{array}{c}\text { downstream } \\
\text { surface }\left(\mathrm{m}^{2}\right)\end{array}$ & $\begin{array}{c}\text { Distance } \\
\text { downstream } \\
\text { and dam }(\mathrm{m})\end{array}$ & Notes \\
\hline ASMIR & 5 & 3 & 5 & 5 & 4 & 4.5 \\
AL WAHDA & 1 & 6 & 3 & 3 & 1 & 2.8 \\
AL HANSALI & 3 & 4 & 2 & 6 & 6 & 4.2 \\
MIDELT & 5 & 1 & 4 & 1 & 1 & 2.4 \\
MLY ABDELAH & 4 & 3 & 1 & 2 & 4 & 2.8 \\
ABDELMOUMEN & 3 & 4 & 6 & 4 & 4 & 4.6 \\
\hline
\end{tabular}

Thus, the site chosen as the installation of the pumped hydro station is the site of Abdelmoumen. The site of the pumped hydro station Abdelmoumen is situated closer to the existing restraint of the dam Abdelmoumen [figure 5].

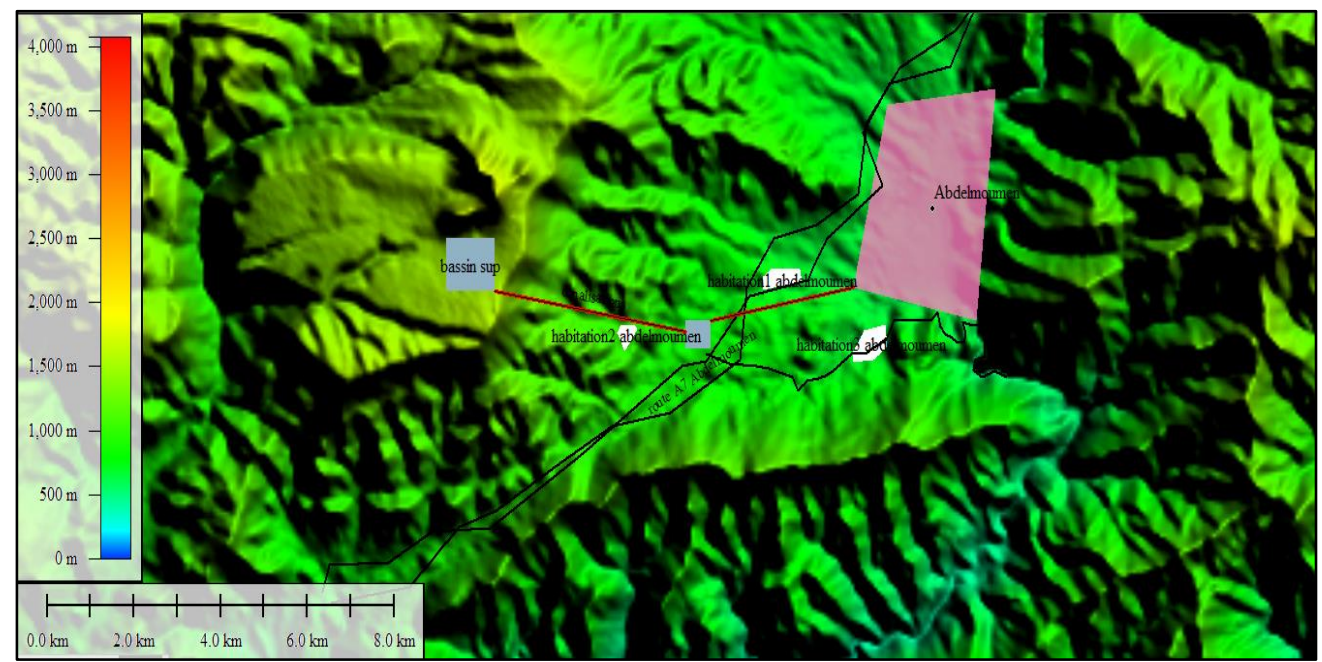

Figure 5: Topographic criteria of Abdelmoumen site

Table 3: Site Criteria

\begin{tabular}{cccccccc}
\hline $\begin{array}{c}\text { Highlight } \\
(\mathrm{m})\end{array}$ & $\begin{array}{c}\text { Uneven } \\
(\mathrm{m})\end{array}$ & $\begin{array}{c}\text { upstream } \\
\text { surface } \\
\left(\mathrm{m}^{2}\right)\end{array}$ & $\begin{array}{c}\text { downstream } \\
\text { surface }\left(\mathrm{m}^{2}\right)\end{array}$ & $\begin{array}{c}\text { Upstream } \\
\text { volume } \\
\left(\mathrm{m}^{3}\right)\end{array}$ & $\begin{array}{c}\text { Downstream } \\
\text { volume }\left(\mathrm{m}^{3}\right)\end{array}$ & $\begin{array}{c}\text { Pipelines } \\
\text { (amont- } \\
\text { aval) }(\mathrm{m})\end{array}$ & $\begin{array}{c}\text { Pipeline } \\
\text { (aval-prise } \\
\text { d'eau })(\mathrm{m})\end{array}$ \\
\hline 1550 & 800 & 261000 & 124950 & 2610000 & 749700 & 3980 & 2801 \\
\hline
\end{tabular}

The general access to the site of the project pumped hydro station Abdelmoumen is made from the city of Agadir by borrowing the main road (RP40) leading to Marrakesh in the village Bigoudine situated near the zone of the project.

The Municipality of BIGOUDINE where is located three under zones of the project dependent on the Province of Taroudant which is a part of the Region SOUSS MASSED DERAA. Economic activities are little developed in the municipality of Bigoudine.

The rural district of Bigoudine pulls resources of the agriculture, the breeding and the exploitation of the Argan tree. But for our project there is no farmland or houses near our site. 
The project is situated in the Moroccan southwest, is approximately between $9,6^{\circ}$ and $7,47^{\circ}$ of longitude west and between $29,70^{\circ}$ and $31,11^{\circ}$ of north latitude and more particularly in the western part of the chain of the High Atlas.

\section{Sizing of the pumping station}

In the big modern networks of electricity, the thermal production (of classic origin or nuclear power) takes a more and more important place with regard to the hydraulic production [11]. On the other hand, she does not allow to assure easily the necessary modulation to follow important and rough variations of the consumption. As a result, we have to have one reserve of energy which can be freed very quickly at the deliberate moment, where came the idea to use the surplus of electricity of off-peak hours to accumulate some potential energy by pumping water in the upper reservoirs and to restore it then to the rush hours. It is the role of the turbinespumps which accept easily the fast variations of load [12].

determination of the main components of the pumped hydro station

According to the production of three studied wind farms, we need to store a power of $50 \mathrm{MW}$, and according to the topographic study we have a fall of $800 \mathrm{~m}$.

\section{Choice of the turbine}

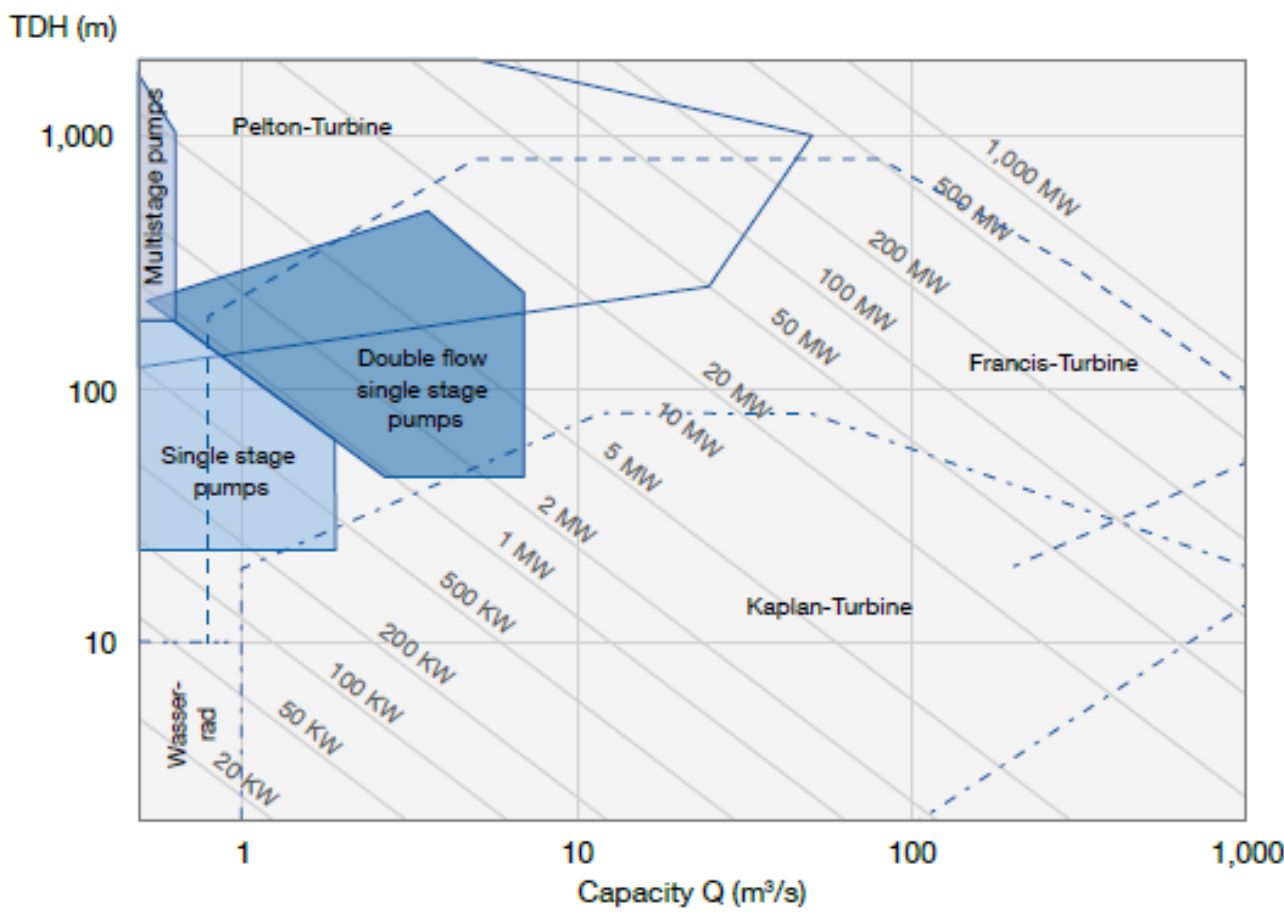

Figure 6: Application diagram of turbines

According to [Figure 6] for a fall of $800 \mathrm{~m}$ and for a power of $50 \mathrm{MW}$, a pelton turbine will be suitable for our station.

Calculation of the flow of the turbine;

Then, $Q=8 \mathrm{~m}^{3} / \mathrm{s}$

$$
P_{h}=\rho g Q H r
$$

Calculation of the diameter of the turbine

The speed of water is given by:

$V=125 \mathrm{~m} / \mathrm{s}$

$$
V=\sqrt{2 \cdot g \cdot H}
$$

$$
Q=V S
$$


The section of passage is given by:

$$
S=\frac{\pi D^{2}}{4}
$$

Then; $D=30 \mathrm{~cm}$

What allows us to calculate the rotation velocity:

$$
N=0,48 . N_{\text {vide }}
$$

Where

$$
N_{\text {vide }}=\frac{60 . V}{\pi D}
$$

So; $N=3800 \operatorname{tr} / m n$

\section{Choice of the pump}

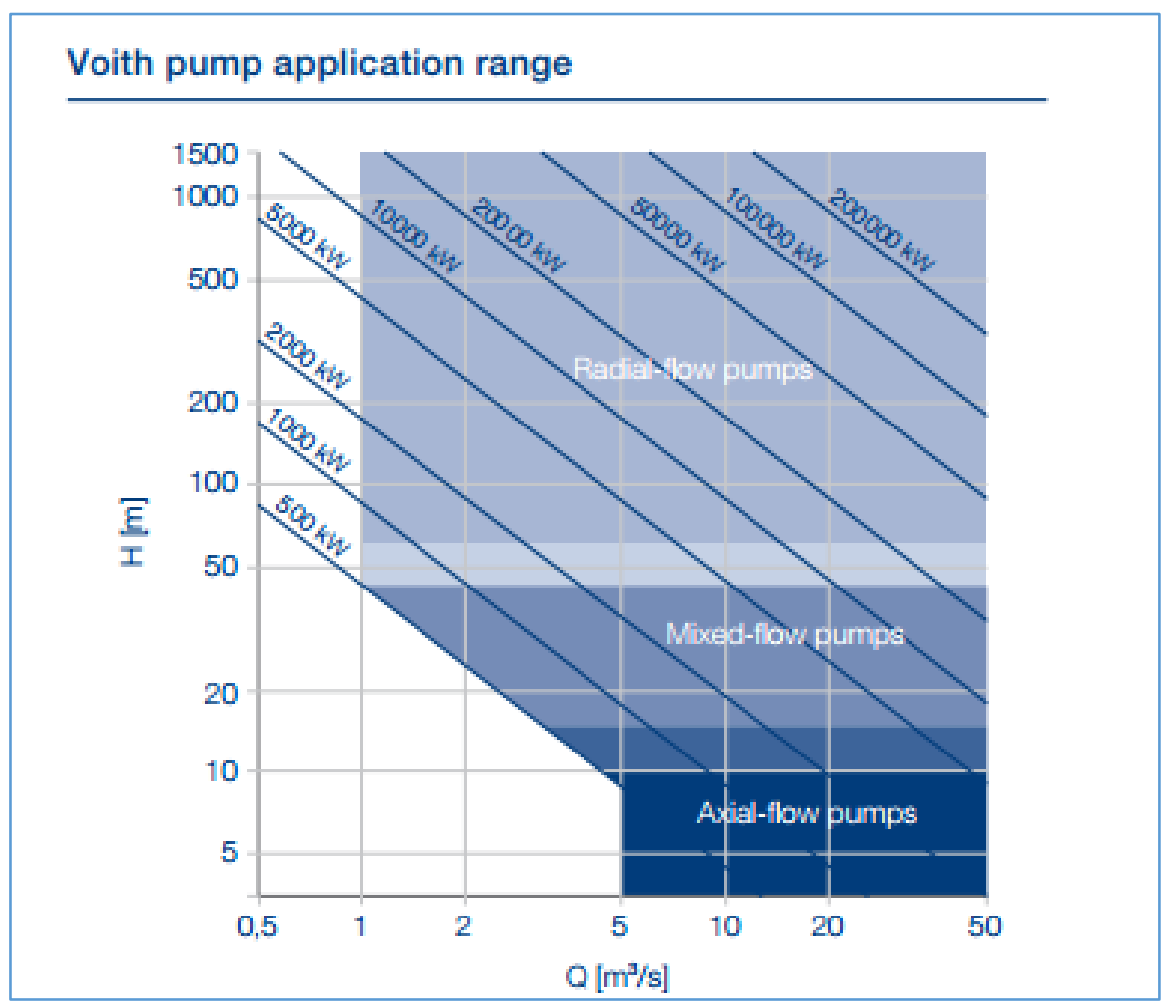

Figure 7: Application diagram of pumps

According to the diagram above [Figure 7], the type of pump that will be suitable to our station is the radial pump.

Yet for the power that we are going to choose for the pump, should be lower than the rate of the turbinage, because of the sizing of ponds, the downstream volume is lower than the upstream volume. Therefore, the power of turbinage will be more important than the power of pumping that will be $1 / 3$ of the power installed as power of the pump.

Thus we have a pump of a power of $15 \mathrm{MW}$ and a height of $800 \mathrm{~m}$ we find according to the relation of the hydraulic power the flow of pumping:

$$
Q=\frac{P}{\rho \cdot g \cdot H \cdot r}
$$


So; $Q=2,4 \mathrm{~m}^{3} / \mathrm{s}$

$$
V=125 \mathrm{~m} / \mathrm{s}
$$

$\mathrm{D}=26 \mathrm{~cm}$

A centrifugal pump must be chosen according to certain real and necessary characteristics for a correct sizing, such as the hydraulic power, the flow and the total manometric height [13].

Total manometric height: is the sum of the geometrical height in the levels of the liquid and the losses of load caused by internal frictions that form in the passage of the liquid in pipes, in pump and hydraulic material.

$$
T M H=H g+\Delta p c
$$

Calculation of the losses of load

A real fluid, in movement, undergoes losses of energy due to the frictions on the walls of the pipe (linear losses of load) or on the accidents of route (singular losses of load).

The linear losses appear along the pipes. The singular losses appear on special parts, which modify the direction or the section of passage of the fluid.

The linear losses of load can be calculated with:

$$
\Delta P_{\text {Linear }}=\lambda \frac{\rho V^{2}}{2} \frac{L}{D}
$$

The singular losses of load can be calculated with:

$$
\begin{gathered}
R e=\frac{V * D}{\vartheta} \\
R e=\frac{4 Q}{\pi \cdot \vartheta \cdot D}
\end{gathered}
$$

$$
\Delta p_{\text {singulière }}=K \frac{\rho V^{2}}{2}
$$

Because of the small size of the diameter of the section of passage, and not enough data to calculate the losses of loads we had to use the efficiency method. We decided then to limit all the energy losses to $25 \%$ of the energy on a cycle. We wish to obtain a minimal yield of $80 \%$ cycle.

Thus, the losses of loads on a cycle are given by the following equation:

$$
\begin{aligned}
\eta_{\text {pipes }}^{2} \cdot \eta_{T} \cdot \eta_{P} \cdot \eta_{\text {alt }}^{2} \cdot \eta_{\text {transf }}^{2}= & \eta_{\text {cycle }} \\
\eta_{\text {cycle }} & =4.5 \%
\end{aligned}
$$

We find losses of loads $4.5 \%$. This result corresponds to total losses of load of:

The total manometric height of the pump is

$$
\begin{gathered}
L L_{\text {tot }}=800 * \frac{4,5}{100} \\
L L_{\text {tot }}=36 \mathrm{~m}
\end{gathered}
$$

$$
T M H=836 m
$$

\section{Choice of the pipelines}

According to the option Cut and Fil of the software Global Mapper, this plan [figure 8] shows the profile of the station of Abdelmoumen with its upper and lower ponds, the location of the group turbine pump which is situated next to the lower pond to take advantage at the most of the fall, as well as the pipe which can pass inside the mountain to have a high potential during the fall it will be expensive seen the loads of the civil engineering, either fixed to the descent but with an a little bit low potential. 


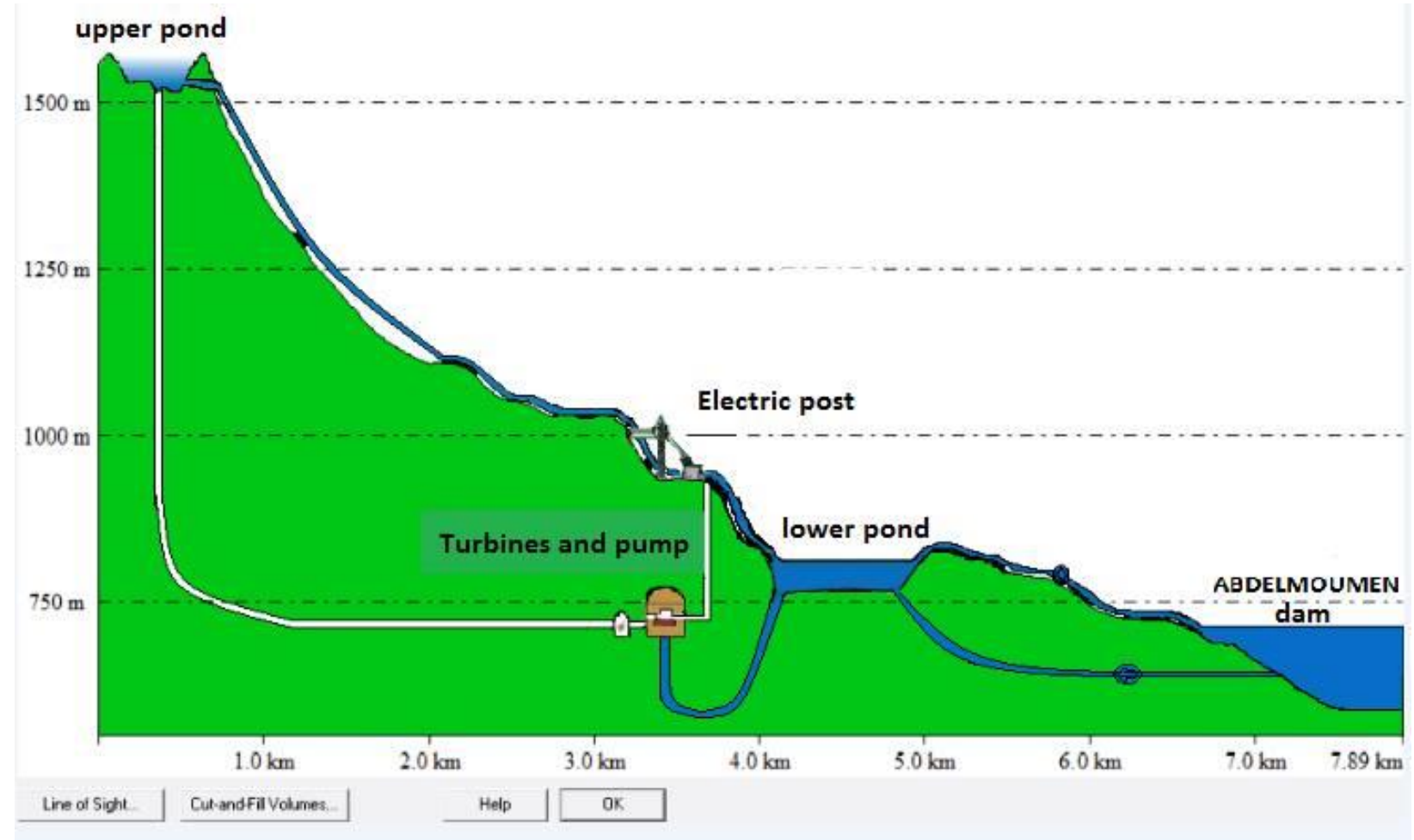

Figure 8: Profile of the pumped hydro station of Abdelmoumen realized by global mapper software

A pressure pipe is an assembly of pipes, transporting some water under pressure of an upper pond situated upstream up to a hydroelectric power plant situated downstream [14]. It is characterized by: Its length. Its diameter.

Table 4: Length of the pipelines

\begin{tabular}{ll}
\hline Length between upstream-downstream & Length between downstream-intake of water \\
\hline $3980 \mathrm{~m}$ & $2801 \mathrm{~m}$ \\
\hline
\end{tabular}

The diameter of the pipelines is $1 \mathrm{~m}$.

An evaluation of the amount of water that could be pumped in both dams and the energy that could be produced from the stored electricity surplus are carried out in this paper, in order to select the most suitable dam to implement the hydro pumped storage power plant and store the electricity surplus [15].

\section{CONCLUSION}

The objective of this study is to combine between two kinds of renewable energy systems; wind and hydro: Sizing a pumped hydro station where we can store the production of the three wind farms Haouma, Akhfennir and FOUM El Oued, during the moments of surplus production in the demand. This project collects a lot of information, syntheses and reformulations. According to the results obtained in this paper, combining wind energy with pumped hydro storage system could be a vital solution to solve Morocco's electricity crisis when combined with large-scale development, with energy storage, may result in significant energy production cost reduction.

To lead a study on several successive stages is very enriching because we obtain a global vision on the way of leading a project. However, future research should also include stability analysis of the power system, especially when studying high penetration levels in order to ensure reliability of the system and enable a cost effective integration of the whole project. Thus, the stochastic behavior of wind speed leads to significant disharmony between wind energy production and electricity demand. Hence, the prospect of creating a combined wind-hydro energy station is found to be a vital issue. Finally, it is commendable to take advantage of the study that we made and deepen it to have an idea on the works of the department of the civil engineering as well as on the financial costs. Future research should also include a dynamic stability analysis of the power system, especially when studying high power wind penetration levels in order to ensure reliability of the system and enable a cost effective integration of the whole project. 


\section{REFERENCES}

1. J. K. Kaldellis, "The wind potential impact on the maximum wind energy penetration in autonomous electrical grids," Renew. Energy, 33,(7), 1665-1677, 2008

2. R. Segurado, J. F. A. Madeira, M. Costa, N. Duić, and M. G. Carvalho, “Optimization of a wind powered desalination and pumped hydro storage system,” Appl. Energy, 177, 487-499, 2016.

3. F. Klumpp, "Comparison of pumped hydro, hydrogen storage and compressed air energy storage for integrating high shares of renewable energies -Potential, cost-comparison and ranking," J. Energy Storage, 8, 119-128, 2016.

4. J. S. Anagnostopoulos and D. E. Papantonis, "Simulation and size optimization of a pumped-storage power plant for the recovery of wind-farms rejected energy," Renew. Energy, 33(7), 1685-1694, 2008.

5. J. P. Deane, B. P. Ó Gallachóir, and E. J. McKeogh, "Techno-economic review of existing and new pumped hydro energy storage plant,” Renew. Sustain. Energy Rev., 14, (4), 1293-1302, 2010.

6. L. E. Groupe, P. Le, and P. Puissant, "Nouveau groupe de production d' hydroelectricite de la coche," 2013.

7. L.-M. Jacquelin, O. Lacroix, and M. Bordeleau, "Le stockage d'énergie - Enjeux, solutions techniques et opportunités de valorisation," 33, 1-18, 2012.

8. R. Saidur, M. R. Islam, N. A. Rahim, and K. H. Solangi, “A review on global wind energy policy,” Renew. Sustain. Energy Rev., 14, (7), 1744-1762, 2010.

9. M. Kapsali, J. S., Anagnostopoulos, "Investigating the role of local pumped-hydro energy storage in interconnected island grids with high wind power generation,” Renewable Energy, 114, 614-628, 2017.

10. M. Kapsali and J. K. Kaldellis, "Combining hydro and variable wind power generation by means of pumped-storage under economically viable terms,” Appl. Energy, 87(11), 3475-3485, 2010.

11. J. K. Kaldellis, M. Kapsali, and K. A. Kavadias, "Energy balance analysis of wind-based pumped hydro storage systems in remote island electrical networks," Appl. Energy, 87(8), 2427-2437, 2010.

12. G. de Oliveira e Silva and P. Hendrick, "Pumped hydro energy storage in buildings," Appl. Energy, 179, 1242-1250, 2016.

13. P. Cooper et al., Performance of Centrifugal Pumps, Third Edition. Elsevier Ltd, 2008.

14. I. Sol-structure, "Projet de Fin d' Etudes" 1-49, 2013.

15. G. Al Zohbi, P. Hendrick, C. Renier, P. Brouillard, "The contribution of wind-hydro pumped storage systems in meeting Lebanon's electricity demand," International Journal of Hydrogen Energy, 41, 6996-7004, 2016.

16. D. Al Katsaprakakis, D. G. Christakis, A. Zervos, D. Papantonis, and S. Voutsinas, "Pumped storage systems introduction in isolated power production systems," Renew. Energy, 33(3), 467-490, 2008. 